\title{
Long-Term Efficacy of Adding Fenofibric Acid to Moderate-Dose Statin Therapy in Patients with Persistent Elevated Triglycerides
}

\author{
Christie M. Ballantyne • Peter H. Jones • \\ Maureen T. Kelly • Carolyn M. Setze • Aditya Lele • \\ Kamlesh M. Thakker • James C. Stolzenbach
}

Published online: 18 March 2011

(C) The Author(s) 2011. This article is published with open access at Springerlink.com

\begin{abstract}
Objective The objective of this study was to evaluate the long-term efficacy of adding fenofibric acid to moderatedose statin therapy in patients at goal for low-density lipoprotein cholesterol (LDL-C) but with persistent hypertriglyceridemia.

Methods This is a post hoc analysis of a subset of patients $(N=92)$ with mixed dyslipidemia treated with moderatedose statin (rosuvastatin $20 \mathrm{mg}$, simvastatin $40 \mathrm{mg}$, or atorvastatin $40 \mathrm{mg}$ ) for 12 weeks in three controlled trials who had achieved LDL-C $<100 \mathrm{mg} / \mathrm{dL}$ but whose triglycerides remained $>200 \mathrm{mg} / \mathrm{dL}$, and had fenofibric acid $135 \mathrm{mg}$ added to the moderate-dose statin in a 52-week open-label extension study. Lipid and apolipoprotein (Apo) values and the proportion of patients meeting individual and combined treatment targets with combination therapy were determined at scheduled visits during the 52-week study and compared with baseline (start of extension study).

Results Addition of fenofibric acid to moderate-dose statin for 52 weeks resulted in significant $(P<0.001)$ improvements in non-high-density lipoprotein cholesterol (nonHDL-C; $-9.0 \%)$, ApoB (-9.8\%), HDL-C (14.9\%), and triglycerides $(-37.6 \%)$ compared with baseline. At final
\end{abstract}

C. M. Ballantyne $(\bowtie) \cdot$ P. H. Jones

Baylor College of Medicine and Methodist DeBakey Heart and

Vascular Center,

6565 Fannin St., Room A601,

Houston, TX 77030, USA

e-mail: cmb@bcm.tmc.edu

M. T. Kelly • C. M. Setze • A. Lele $\cdot$ K. M. Thakker •

J. C. Stolzenbach

Abbott,

Abbott Park, IL, USA visit, greater proportions of patients achieved optimal levels of individual parameters as well as combined targets of LDL-C+non-HDL-C (60.0\% vs 52.2\%), LDL-C+nonHDL-C + ApoB (53.3\% vs 37.8\%, $P=0.007)$, and LDL-C + non-HDL-C + ApoB + HDL-C + triglycerides $(25.6 \%$ vs $0.0 \%$ ) than at baseline.

Conclusions The addition of fenofibric acid to moderate-dose statin in patients whose LDL-C was optimal but whose triglycerides remained $>200 \mathrm{mg} / \mathrm{dL}$ led to additional improvements in non-HDL-C, ApoB, HDL-C, and triglycerides that resulted in greater proportions of patients attaining optimal levels of the individual parameters as well as simultaneously achieving optimal levels of these parameters and LDL-C.

Key words Dyslipidemia · Hypertriglyceridemia · Statin . Fenofibric acid

\section{Introduction}

Mixed dyslipidemia, characterized by elevated levels of triglycerides (TG), low levels of high-density lipoprotein cholesterol (HDL-C), elevated low-density lipoprotein cholesterol (LDL-C), and a preponderance of small dense particles is associated with additional coronary heart disease (CHD) risk, compared with elevated LDL-C alone [1-4]. National Cholesterol Education Program (NCEP) Adult Treatment Panel (ATP) III identifies both elevated TG and low levels of HDL-C as markers of increased cardiovascular risk given that each is independently associated with CHD risk [5]. Although LDL-C remains the primary therapeutic target in the management of dyslipidemia, NCEP ATP III also recommends non-HDL$\mathrm{C}$ as a secondary target of treatment in patients at LDL-C 
goal with persistent hypertriglyceridemia ( $\mathrm{TG} \geq 200 \mathrm{mg} / \mathrm{dL}$ ). As an alternative to intensifying LDL-C-lowering therapy or if tolerance to a statin becomes an issue, the addition of nicotinic acid or a fibrate to LDL-C-lowering treatment is recommended to achieve a non-HDL-C goal no higher than $30 \mathrm{mg} / \mathrm{dL}$ above the patient's LDL-C goal [5].

The choline salt of fenofibric acid formulated as entericcoated mini-tablets in a delayed-release capsule (Trilipix, Abbott, Abbott Park, IL) is indicated for combined use with a statin to reduce TG and increase HDL-C in CHD or a CHD risk equivalent patients with mixed dyslipidemia who are on optimal statin therapy to achieve their LDL-C goal. In three similarly designed 12-week, controlled clinical studies, fenofibric acid coadministered with low- or moderate-dose rosuvastatin, simvastatin, or atorvastatin was found to be efficacious and well tolerated in patients with mixed dyslipidemia [6-8]. A subsequent 52-week, open-label extension of the three controlled studies evaluated the long-term safety and efficacy of fenofibric acid coadministered with moderate-dose statin [9]. This analysis of the extension study evaluated the long-term efficacy of adding fenofibric acid $135 \mathrm{mg}$ to moderate-dose statin therapy (rosuvastatin $20 \mathrm{mg}$, simvastatin $40 \mathrm{mg}$, or atorvastatin $40 \mathrm{mg}$ ) in patients with LDL-C $<100 \mathrm{mg} / \mathrm{dL}$ but with TG above $200 \mathrm{mg} / \mathrm{dL}$ after 12 weeks of treatment with moderate-dose statin monotherapy in the controlled studies.

\section{Methods}

This is a post hoc analysis of data collected during a 52week open-label extension study of three similarly designed phase 3, 12-week, multicenter, randomized, controlled, double-blind studies (NCT00300482, NCT00300469, NCT00300456). The studies were conducted between March, 2006 and March, 2008. All patients provided written informed consent and the studies were approved by the institutional review board at each center. Eligible patients for the three controlled studies were adults $\geq 18$ years of age with mixed dyslipidemia defined as screening $\mathrm{TG} \geq$ $150 \mathrm{mg} / \mathrm{dL}$, LDL-C $\geq 130 \mathrm{mg} / \mathrm{dL}$, and HDL-C $<40 \mathrm{mg} / \mathrm{dL}$ for men and $<50 \mathrm{mg} / \mathrm{dL}$ for women. Exclusion criteria included pregnancy, evidence of unstable cardiovascular disease, type 1 diabetes mellitus, and uncontrolled type 2 diabetes mellitus with hemoglobin A1c $>8.5 \%$. Patients who completed the controlled studies were eligible to enroll in the open-label extension study.

Details of the study design for the three controlled studies and the open-label extension study have been published previously (Fig. 1) [6-9]. Each controlled study used a separate statin (rosuvastatin, simvastatin, or atorvastatin). Briefly, in these controlled studies, after a 6-week diet run-in/lipid therapy washout period, patients meeting the eligibility criteria were randomized to 12 weeks of blinded treatment with fenofibric acid $135 \mathrm{mg}$; monotherapy with low- (rosuvastatin $10 \mathrm{mg}$, simvastatin $20 \mathrm{mg}$, and atorvastatin $20 \mathrm{mg}$ ), moderate- (rosuvastatin $20 \mathrm{mg}$, simvastatin $40 \mathrm{mg}$, and atorvastatin $40 \mathrm{mg}$ ), or high-dose (rosuvastatin $40 \mathrm{mg}$, simvastatin $80 \mathrm{mg}$, and atorvastatin $80 \mathrm{mg}$ ) statin; or fenofibric acid $135 \mathrm{mg}+$ low- or moderatedose statin. The high-dose statin monotherapy groups enrolled half the number of patients as the other treatment arms and served as a reference arm for safety in each study.

In the extension study, all patients received fenofibric acid $135 \mathrm{mg}$ +moderate-dose statin (rosuvastatin $20 \mathrm{mg}$, simvastatin $40 \mathrm{mg}$, or atorvastatin $40 \mathrm{mg}$ ) for up to 52 weeks. Patients in the extension study received the same statin that was used in the controlled study in which they had participated. At protocol-specified study visits, patients were evaluated for efficacy and safety measures.

\section{Patient population}

The inclusion criteria specified for the present analysis required patients to: (a) have been treated with moderatedose statin monotherapy (rosuvastatin $20 \mathrm{mg}$, simvastatin $40 \mathrm{mg}$, or atorvastatin $40 \mathrm{mg}$ ) for 12 weeks in one of the three controlled studies; (b) have entered and received $\geq 1$ dose of treatment with fenofibric acid +moderate-dose statin in the 52-week open-label extension study; and (c) have LDL-C $<100 \mathrm{mg} / \mathrm{dL}$ and TG $>200 \mathrm{mg} / \mathrm{dL}$ at the start of the open-label extension study.

\section{Efficacy and safety measures}

The efficacy measures for the present analyses were as follows: (a) percent changes in lipids (non-HDL-C, TG, LDL-C, and HDL-C) and apolipoprotein (Apo) B levels at scheduled time points in the 52-week extension study relative to start of treatment with the combination of fenofibric acid and moderate-dose statin (hereafter referred to as baseline); (b) proportion of patients achieving NCEP ATP III [5] and/or consensus [10] recommended optimal levels of LDL-C $(<100 \mathrm{mg} / \mathrm{dL})$, non-HDL-C $(<130 \mathrm{mg} /$ $\mathrm{dL})$, ApoB $(<90 \mathrm{mg} / \mathrm{dL})$, HDL-C $(>40 \mathrm{mg} / \mathrm{dL}$ in men and $>50 \mathrm{mg} / \mathrm{dL}$ in women $)$ and $\mathrm{TG}(<200 \mathrm{mg} / \mathrm{dL}$ and $<150 \mathrm{mg} /$ $\mathrm{dL}$ ) at baseline, week 12, and final visit of the extension study; and (c) proportion of patients simultaneously achieving optimal levels of LDL-C+non-HDL-C, LDL-C + HDL-C, LDL-C + non-HDL-C + ApoB, and LDL-C+nonHDL-C + ApoB + HDL-C + TG at baseline, week 12, and final visit of the extension study. Safety was evaluated based on data collected for adverse events, physical and electrocardiographic examinations, vital sign measurements, and clinical laboratory tests. The adverse events were coded using the Medical Dictionary of Regulatory 
Fig. 1 Design and timeline of the controlled studies and the open-label extension study. Patients with LDL-C $<100 \mathrm{mg} /$ dL but $\mathrm{TG}>200 \mathrm{mg} / \mathrm{dL}$ after receiving moderate-dose statin monotherapy in the controlled studies, who entered and received $\geq 1$ dose of treatment with fenofibric acid + moderate-dose statin in the 52-week extension were included in the analysis
Controlled Studies

12 weeks

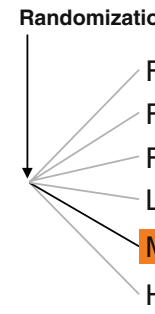

Extension Study

52 weeks
Activities (MedDRA). Muscle-, hepatic-, and renal-related adverse events were considered as events of special interest and were identified utilizing the appropriate standard MedDRA queries.

\section{Statistical analyses}

Mean percent changes from baseline to various time points were calculated for all efficacy parameters and were compared using a paired $t$-test. The number and percentage of patients attaining optimal individual and combined targets at week 12 and final visit (week 52 or earlier) were compared with baseline using McNemar's test, a nonparametric method used to test for marginal homogeneity of categorical data with matched pairs of patients and a dichotomous variable of interest. The test assessed whether the number/proportion of patients meeting optimal targets at baseline and after addition of fenofibric acid to moderatedose statin therapy were different. The assumptions of equality do not hold true if the $P$ value is significant, at which point the proportions indicate the direction of shift. Baseline was defined as the last value prior to the start of open-label combination therapy. The last observation carried forward (LOCF) method was used to impute values for patients with missing postbaseline values in the extension study; baseline values were not carried forward.

\section{Results}

A total of 2,316 patients completed the three 12-week controlled studies, of which 364 were treated with moderate-dose statin monotherapy (rosuvastatin $20 \mathrm{mg}$, simvastatin $40 \mathrm{mg}$, or atorvastatin $40 \mathrm{mg}$ ) in the controlled studies and received at least one dose of fenofibric acid in combination with moderate-dose statin in the open-label extension study. Of the 364 patients, 92 (25\%) had LDL-C $<100 \mathrm{mg} / \mathrm{dL}$ and $\mathrm{TG}>200 \mathrm{mg} / \mathrm{dL}$ at the start of the openlabel extension study. These 92 patients serve as the subgroup for the present analyses.

Baseline characteristics of the subgroup are summarized in Table 1 . The majority of the patients were white (95\%) and the mean age of the subgroup was 54 years. Based on the Framingham risk categorization, $41 \%$ were considered as high-risk patients. At the start of the extension study, mean baseline LDL-C, non-HDL-C, HDL-C, and ApoB were $78.5 \mathrm{mg} / \mathrm{dL}, 133.6 \mathrm{mg} / \mathrm{dL}, 38.8 \mathrm{mg} / \mathrm{dL}$, and $91.5 \mathrm{mg} /$ $\mathrm{dL}$, respectively; median triglycerides were $249.5 \mathrm{mg} / \mathrm{dL}$ (Table 1).

As shown in Fig. 2, addition of fenofibric acid to moderate-dose statin for 52 weeks resulted in statistically significant mean percent reductions in non-HDL-C, ApoB, and TG at each visit relative to baseline. At final visit, the mean percent reductions after the addition of fenofibric acid to moderate-dose statin in non-HDL-C, ApoB, and TG were $9.0 \%, 9.8 \%$, and $37.6 \%$, respectively $(P<0.001$ for all comparisons). HDL-C and LDL-C levels significantly increased at each visit relative to baseline; mean percent increases at final visit in HDL-C and LDL-C were $14.9 \%$ and $12.1 \%$, respectively $(P<0.001)$. Similar changes in lipid and nonlipid parameters were noted when the data were analyzed as observed $(n=72)$.

Adding fenofibric acid to moderate-dose statin numerically increased the proportion of patients with optimal nonHDL-C $(<130 \mathrm{mg} / \mathrm{dL})$ levels from $52.2 \%$ at baseline to $63.3 \%$ and $64.4 \%$ at week 12 and final visit, respectively. Also, the proportion of patients with optimal ApoB levels $(<90 \mathrm{mg} / \mathrm{dL})$ significantly increased to $61.1 \%$ at week 12 and $66.7 \%$ at final visit, compared with $40 \%$ at baseline ( $P \leq 0.001$ for both comparisons). Optimal HDL-C levels of $>40 \mathrm{mg} / \mathrm{dL}$ in men and $>50 \mathrm{mg} / \mathrm{dL}$ in women were achieved by $33.3 \%$ of patients at week 12 , and $47.8 \%$ of patients at final visit, compared with $18.9 \%$ at baseline $(P=$ 0.02 and $P<0.001$, respectively). Additionally, the proportion of patients with TG $<200 \mathrm{mg} / \mathrm{dL}$ was $66.7 \%$ and $70 \%$ at week 12 and final visit, respectively, compared with $0 \%$ at baseline (by definition of the population). The median baseline TG for patients who achieved optimal TG ( $<200 \mathrm{mg} / \mathrm{dL}$ ) was $242 \mathrm{mg} / \mathrm{dL}$ (interquartile range: $227-$ $270 \mathrm{mg} / \mathrm{dL}$ ), compared with a median baseline TG of $281 \mathrm{mg} / \mathrm{dL}$ (interquartile range: $240-557 \mathrm{mg} / \mathrm{dL}$ ) for those whose TG was not optimal ( $\geq 200 \mathrm{mg} / \mathrm{dL}$ ). Furthermore, the proportion of patients with $\mathrm{TG}<150 \mathrm{mg} / \mathrm{dL}$ following combination treatment was $48.9 \%$ at final visit. Finally, the 
Table 1 Baseline characteristics of the subgroup population

\begin{tabular}{|c|c|}
\hline Characteristic & $N=92$ \\
\hline \multicolumn{2}{|l|}{ Gender, n (\%) } \\
\hline Women & $39(42.4)$ \\
\hline \multicolumn{2}{|l|}{ Race, n (\%) } \\
\hline White & 87 (94.6) \\
\hline Black & $3(3.3)$ \\
\hline Other & $2(2.2)$ \\
\hline \multicolumn{2}{|l|}{ Ethnicity, n (\%) } \\
\hline Hispanic & $10(10.9)$ \\
\hline \multicolumn{2}{|l|}{ Age, y } \\
\hline Mean (SD) & $54.5(10.93)$ \\
\hline$\geq 65, \mathrm{n}(\%)$ & $16(17.4)$ \\
\hline \multicolumn{2}{|l|}{ Tobacco use, n (\%) } \\
\hline Tobacco user & $26(28.3)$ \\
\hline Former & $26(28.3)$ \\
\hline Never & $40(43.5)$ \\
\hline \multicolumn{2}{|l|}{ Medical history, n (\%) } \\
\hline Hypertension & $47(51.1)$ \\
\hline Diabetes mellitus type 2 & $24(26.1)$ \\
\hline Metabolic syndrome $^{\mathrm{a}}$ & $69(75.0)$ \\
\hline Coronary artery disease & $5(5.4)$ \\
\hline \multicolumn{2}{|l|}{ Framingham risk category, $\mathrm{n}(\%)$} \\
\hline High & $38(41.3)$ \\
\hline Moderate & $39(42.4)$ \\
\hline Low & $15(16.3)$ \\
\hline \multicolumn{2}{|l|}{ Baseline lipids, mg/dL } \\
\hline Low-density lipoprotein cholesterol, mean (SD) & $78.5(13.64)$ \\
\hline Non-high-density lipoprotein cholesterol, mean (SD) & $133.6(36.45)$ \\
\hline High-density lipoprotein cholesterol, mean (SD) & $38.8(7.31)$ \\
\hline Triglycerides, median (min, max) & $249.5(200.9,2700.0)$ \\
\hline Apolipoprotein B, mean (SD) & $91.5(14.19)$ \\
\hline
\end{tabular}

${ }^{a}$ Determined according to National Cholesterol Education Program Adult Treatment Panel III definition [5] observed $(n=72)$ and the improvements noted at week 12 were sustained through week 52 .

The addition of fenofibric acid to moderate-dose statin therapy was generally well tolerated for 52 weeks. The most frequently reported adverse events (>5\%) were constipation, gastroenteritis, bronchitis, influenza, nasopharyngitis, sinusitis, upper respiratory track infection, arthralgia, back pain, muscle spasms, dizziness, headache, cough, and pharyngolaryngeal pain. The incidence of adverse events and laboratory measurements related to muscle, hepatic, and renal systems are shown in Table 2. Over the 52-week treatment period, no rhabdomyolysis was reported and the incidence of myalgia (4.3\%) and myositis $(1.1 \%)$ was low. Increases in creatine phosphokinase (CK) $>10 \mathrm{x}$ upper limit of normal (ULN) was reported for 1 patient. Alanine aminotransferase (ALT) $>3 \mathrm{x}$ ULN on 2 consecutive occasions was reported for 1 patient; no patients had aspartate aminotransferase (AST) $>3 x$ ULN on 2 consecutive occasions. 
Fig. 2 Mean percent changes from baseline in lipid and apolipoprotein levels over 52 weeks after addition of fenofibric acid to moderate-dose statin therapy. Baseline was defined as the value at the end of 12 weeks of moderate-dose statin monotherapy in the controlled study, prior to the start of open-label combination therapy. Data reported are based on last observation carried forward method. P values comparing each visit with baseline were obtained from a paired $t$-test. Statistically significant differences observed at each time point compared with baseline (week 0) for non-HDL-C, ApoB, HDL-C, TG, and LDL-C $(P \leq 0.03$ for all comparisons). At week 16, ApoB was not measured

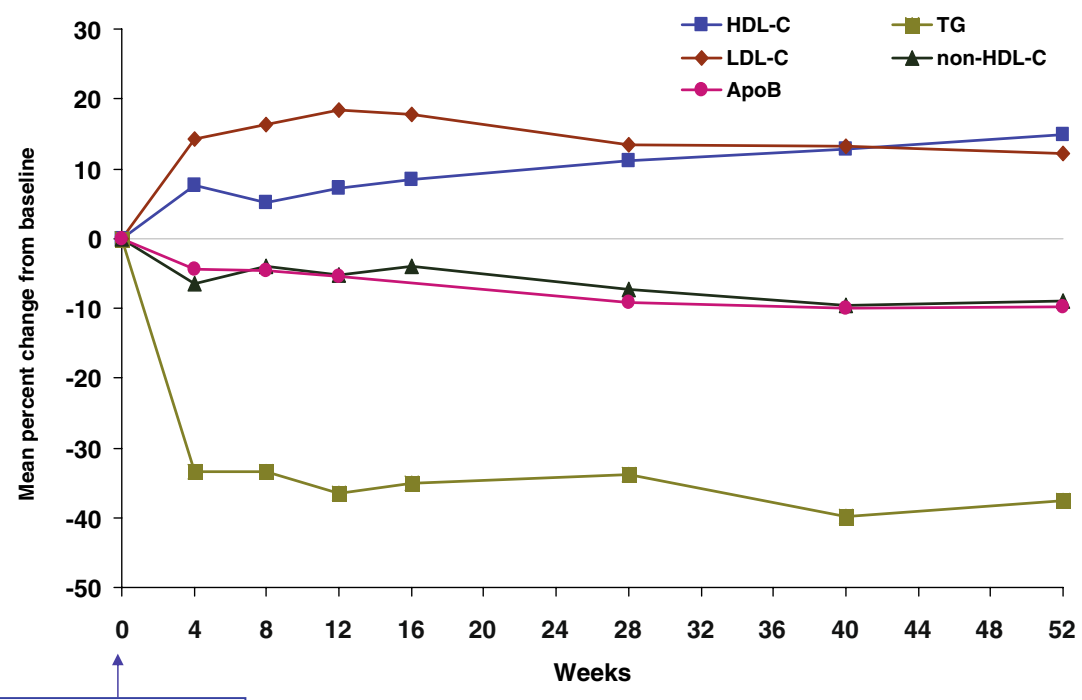

Fenofibric Acid Added to

Moderate-Dose Statin
Fig. 3 Proportion of patients with optimal levels of LDL-C $(<100 \mathrm{mg} / \mathrm{dL})$, non-HDL-C $(<130 \mathrm{mg} / \mathrm{dL})$, ApoB $(<90 \mathrm{mg} /$ $\mathrm{dL})$, HDL-C $(>40 \mathrm{mg} / \mathrm{dL}$ in men and $>50 \mathrm{mg} / \mathrm{dL}$ in women), and TG $(<200 \mathrm{mg} / \mathrm{dL}$ and $<150 \mathrm{mg} /$ $\mathrm{dL}$ ) at baseline (after 12 weeks of treatment with moderate-dose statin) and at week 12 and final visit (week 52) after addition of fenofibric acid to moderate-dose statin therapy. Data reported are based on last observation carried forward method. Statistical comparisons were not performed for LDL-C and TG since, by definition, all patients had optimal levels of LDL-C and no patients had optimal levels of TG at baseline

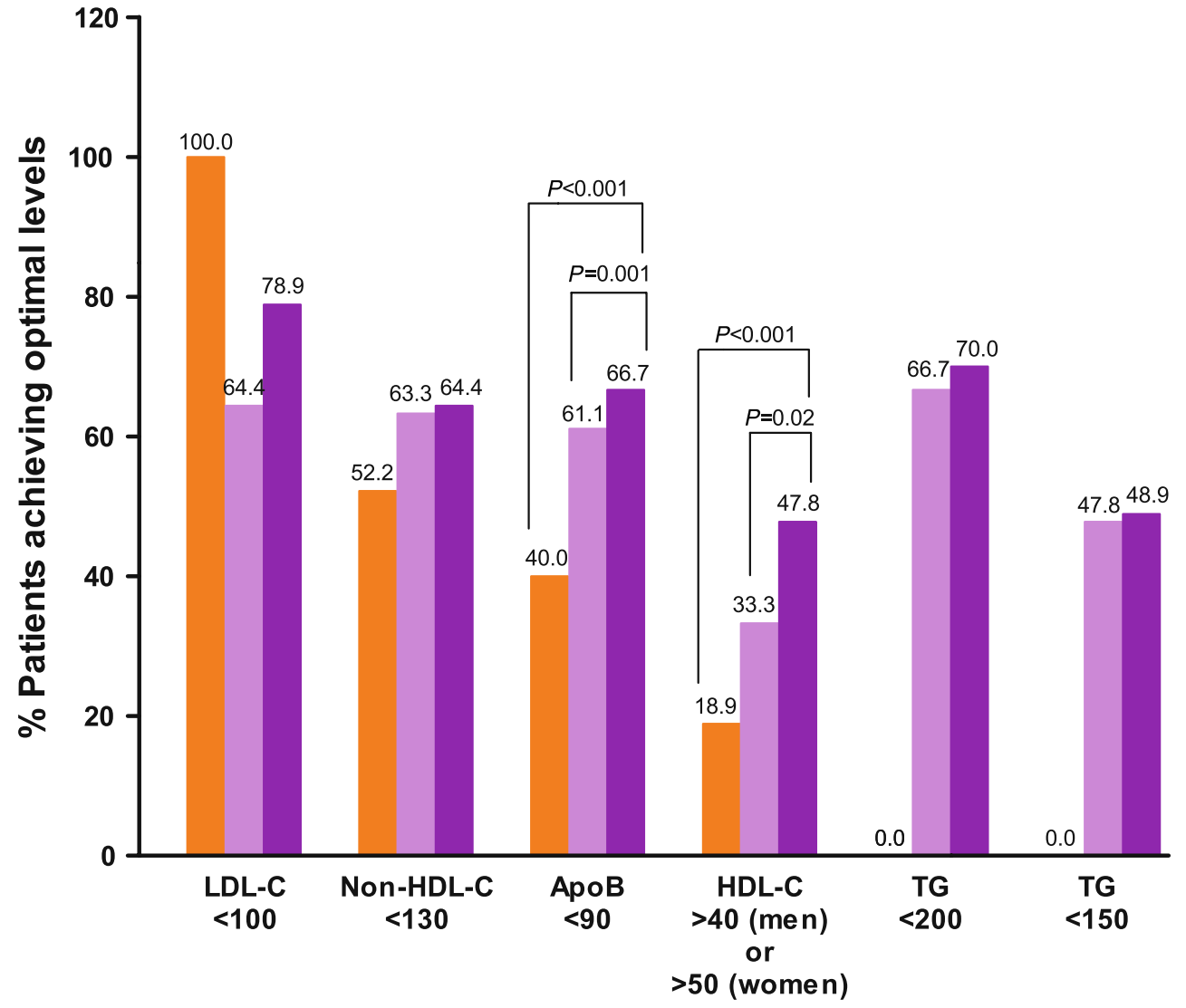

Baseline (after 12-week moderate -dose statin monotherapy)

Final visit (after 52-week therapy with the addition of fenofibric acid to moderate-dose statin)

Week 12 (after 12-week therapy with the addition of fenofibric acid to moderate-dose statin) 


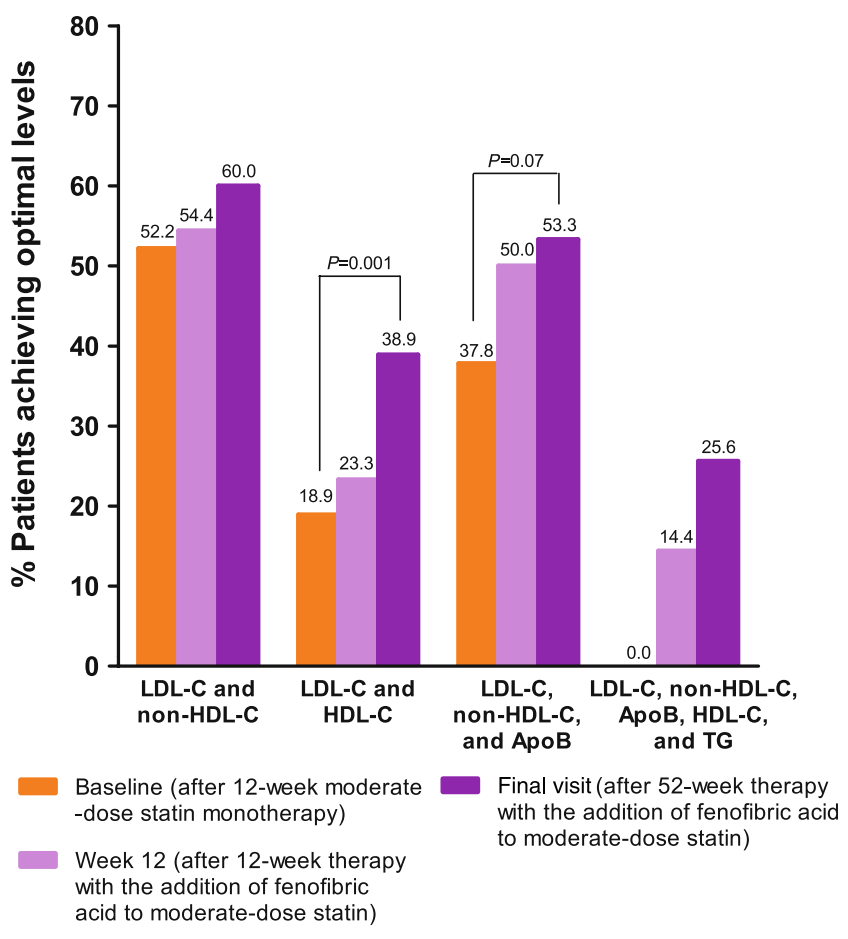

Fig. 4 Proportion of patients simultaneously achieving optimal levels for multiple parameters (LDL-C+non-HDL-C; LDL-C+HDL-C, $\mathrm{LDL}-\mathrm{C}+$ non-HDL-C $+\mathrm{ApoB}$, and LDL-C + non-HDL-C $+\mathrm{ApoB}+$ HDL-C+TG) at baseline (after 12 weeks of treatment with moderate-dose statin) and at week 12 and final visit (week 52) after addition of fenofibric acid to moderate-dose statin therapy. The optimal levels for each parameter were LDL-C $<100 \mathrm{mg} / \mathrm{dL}$, nonHDL-C $<130 \mathrm{mg} / \mathrm{dL}$, HDL-C $>40 \mathrm{mg} / \mathrm{dL}$ for men and $>50 \mathrm{mg} / \mathrm{dL}$ for women, ApoB $<90 \mathrm{mg} / \mathrm{dL}$, and $\mathrm{TG}<150 \mathrm{mg} / \mathrm{dL}$. Data reported are based on last observation carried forward method. Statistical comparisons were not performed for the achievement of optimal levels of the five parameters (LDL-C+non-HDL-C + ApoB $+\mathrm{HDL}-\mathrm{C}+\mathrm{TG}$ ) since, by definition, no patients had optimal levels of $\mathrm{TG}$ at baseline

\section{Discussion}

This post hoc analysis of a 52-week safety and efficacy study of fenofibric acid in combination with moderate-dose statin demonstrated that in patients who were at goal for LDL-C $(<100 \mathrm{mg} / \mathrm{dL})$, but had persistent elevated TG $(>200 \mathrm{mg} / \mathrm{dL})$ after 12 weeks of treatment with a moderate dose-statin, the long-term addition of fenofibric acid resulted in significant improvements in non-HDL-C, ApoB, HDL-C, and TG. In addition, the proportion of patients achieving optimal levels of non-HDL-C, ApoB, HDL-C, and TG, as well as combined targets of these variables and LDL-C increased from baseline to final visit with the addition of fenofibric acid to moderate-dose statin.

The NCEP ATP III guidelines recognize elevated TG as a marker of atherogenic remnant lipoproteins and increased cardiovascular risk [5]. The ATP III recommends non-HDL$\mathrm{C}$, a measure of the cholesterol content in LDL, intermediate-density lipoprotein (IDL), and very-low-density lipoprotein (VLDL) as a secondary treatment target (after LDL-C) in patients with TG $\geq 200 \mathrm{mg} / \mathrm{dL}$. Along with LDL$\mathrm{C}$ and non-HDL-C, the American Diabetes Association/ American College of Cardiology Foundation consensus report has recommended ApoB as both a marker for CHD risk and a target in patients with cardiometabolic risk, whose typical lipoprotein profile includes high TGs and/or low HDL-C [10]. The patients in this analysis, at goal for LDL-C but with elevated TGs despite treatment with moderate-dose statin monotherapy, qualify for the addition of a niacin or a fibrate based on treatment guidelines. As such, both nonHDL-C and ApoB levels were improved from baseline to week 12 and were sustained until week 52 with the addition
Table 2 Incidence of adverse events and laboratory measurements

$A L T$ alanine aminotransferase, AST aspartate aminotransferase, $C K$ creatine phosphokinase, $U L N$ upper limit of normal

\begin{tabular}{lc}
\hline & Incidence, $\mathrm{n}(\%)$ \\
& $N=92$ \\
\hline Hepatic & \\
$\mathrm{ALT}>5 \mathrm{x}$ ULN & $0(0.0)$ \\
$\mathrm{ALT}>3 \mathrm{x}$ ULN on 2 consecutive occasions & $1(1.1)$ \\
$\mathrm{AST}>5 \mathrm{x}$ ULN & $0(0.0)$ \\
AST $>3 \mathrm{x}$ ULN on 2 consecutive occasions & $0(0.0)$ \\
Muscle & \\
$\mathrm{CK}>5 \mathrm{x}$ ULN & $2(2.2)$ \\
$\mathrm{CK}>10 \mathrm{x}$ ULN & $1(1.1)$ \\
Myalgia & $4(4.3)$ \\
Myositis & $1(1.1)$ \\
Rhabdomyolysis & $0(0.0)$ \\
Renal & \\
Creatinine $>2 \mathrm{mg} / \mathrm{dL}$ & $1(1.1)$ \\
Creatinine $\geq 50 \%$ increase from baseline and $>1 \mathrm{x}$ & $6(6.6)$ \\
ULN on a single occasion & \\
Creatinine $\geq 100 \%$ increase from baseline & $1(1.1)$ \\
\hline
\end{tabular}


of fenofibric acid to moderate-dose statin therapy. Furthermore, median TG levels decreased to near $150 \mathrm{mg} / \mathrm{dL}$ at final visit and mean HDL-C levels significantly increased to $>40 \mathrm{mg} / \mathrm{dL}$ at final visit in this subgroup of patients.

In this analysis, the mean baseline LDL-C at the start of the extension study was $79 \mathrm{mg} / \mathrm{dL}$. After the addition of fenofibric acid to moderate-dose statin therapy, mean LDL$\mathrm{C}$ increased to $87 \mathrm{mg} / \mathrm{dL}$ resulting in $21.1 \%$ of patients no longer having LDL-C $<100 \mathrm{mg} / \mathrm{dL}$ at the final visit. However, the percentage of patients with optimal nonHDL-C levels $(<130 \mathrm{mg} / \mathrm{dL})$ increased by $12 \%$ and those with optimal ApoB levels $(<90 \mathrm{mg} / \mathrm{dL})$ increased by $27 \%$ at final visit. These results suggest that the net effect of adding fenofibric acid to moderate-dose statin therapy is an increase in LDL particle size (as measured by the increase in cholesterol content in the LDL fraction) and a reduction in atherogenic particle number as measured by ApoB. The increase in LDL-C noted in this subgroup of patients with hypertriglyceridemia is not unexpected, as baseline TGs have been shown to influence the LDL-C-lowering effect of statin+fibrate combinations (greater reductions with low baseline TGs) [11]. In patients with high TG, treatment with fibrates results in an increase in measured LDL-C content, likely because of fibrate-induced increased lipolysis of TG-rich VLDL particles $[12,13]$ and/or a shift in LDL particle size [14-17]. Despite the benefits in LDL particle size and number, and improvements in other lipid parameters, a patient's CHD risk should be considered when making treatment decisions for patients whose LDL$\mathrm{C}$ is $>100 \mathrm{mg} / \mathrm{dL}$. The primary aim of treatment, according to NCEP ATP III guidelines, is to achieve LDL-C goal $(<100 \mathrm{mg} / \mathrm{dL}$ for high-risk patients, $<130 \mathrm{mg} / \mathrm{dL}$ for moderate-risk patients, and $<160 \mathrm{mg} / \mathrm{dL}$ for low-risk patients). Combination therapy may be considered to treat the secondary non-HDL-C goal in patients with TG $\geq$ $200 \mathrm{mg} / \mathrm{dL}$ only after the LDL-C goal has been reached.

In the present study, the proportion of patients with optimal HDL-C increased by $29 \%$, and $70 \%$ of the patients had TG $<200 \mathrm{mg} / \mathrm{dL}$ by final visit. As a result, a higher percentage of patients had optimal levels of multiple parameters such as LDL-C + non-HDL-C, LDL-C + HDL-C, LDL-C + non$\mathrm{HDL}-\mathrm{C}+\mathrm{ApoB}$, and LDL-C+non-HDL-C $+\mathrm{ApoB}+\mathrm{HDL}-\mathrm{C}$ + TG with the addition of fenofibric acid to moderate-dose statin for 52 weeks. As TG levels at final visit remained $\geq 200 \mathrm{mg} / \mathrm{dL}$ in $30 \%$ of the patients, we compared the baseline TG values of patients who achieved optimal TG versus those whose TG was not optimal. Patients whose TG remained at or above the threshold at final visit started with much higher baseline TG values (median $281 \mathrm{mg} / \mathrm{dL}$ ) than those whose TG dropped below the threshold (median $242 \mathrm{mg} / \mathrm{dL}$ ). Although statin monotherapy is known to reduce TG levels, the final median TG of $152.0 \mathrm{mg} / \mathrm{dL}$ in our study represents a substantial reduction in TG from a baseline median of $249.5 \mathrm{mg} / \mathrm{dL}$ with the addition of fenofibric acid to moderate-dose statin therapy.

Other treatment strategies for normalizing multiple lipid parameters in patients with mixed dyslipidemia include the addition of nicotinic acid or omega 3-fatty acids to statin therapy. Both strategies have been evaluated in long-term safety and efficacy studies and have resulted in improvements of lipid parameters other than LDL-C [18, 19]. Addition of omega-3 fatty acids (as eicosapentaenoic acid) to statin therapy has been shown in one study to significantly reduce major coronary events in patients with hypercholesterolemia although the study did not require elevated TG for patients to enroll [19], while outcomes studies are ongoing to demonstrate the incremental benefit of adding niacin to statin treatment. It should be noted that although the combination of fenofibrate and simvastatin in the Action to Control Cardiovascular Risk in Diabetes (ACCORD) study did not significantly reduce the rate of nonfatal myocardial infarction, nonfatal stroke, or cardiovascular death compared with simvastatin alone, a prespecified analysis demonstrated a $31 \%$ relative risk reduction in cardiovascular events in patients with both high TG $(\geq 204 \mathrm{mg} / \mathrm{dL})$ and low HDL-C $(\leq 34 \mathrm{mg} / \mathrm{dL})$ compared to treatment with statin alone [20]. The data from ACCORD are consistent with other fibrate trials showing that a subset of patients with elevated TGs and low HDL-C have cardiovascular benefit [21-23].

As mentioned earlier, guidelines recommend non-HDL$\mathrm{C}$ and $\mathrm{ApoB}$ as additional secondary targets in patients with $\mathrm{TG} \geq 200 \mathrm{mg} / \mathrm{dL}[5,10,24-26]$. The NEPTUNE II study, a national survey estimating goal attainment with statin therapy, found that achievement of the combined LDL-C + non-HDL-C targets among patients with $\mathrm{TG} \geq 200 \mathrm{mg} / \mathrm{dL}$ ranged from $78 \%$ in the low-risk category to $27 \%$ in the high-risk category [27]. In a separate post hoc study of metabolic syndrome patients, the combined target of LDLC+non-HDL-C was achieved by $67 \%$ of patients after 6 weeks of treatment with rosuvastatin $40 \mathrm{mg}$ [28]. The current analysis suggests that combination therapy with fenofibric acid+moderate-dose statin may offer a strategy to improve these goal attainment observations.

Bays et al. have previously reported the safety findings for the overall population of the open-label extension study [9]. The addition of fenofibric acid to moderate-dose statin for 52 weeks in the current analysis was well tolerated. The incidence of myalgia and myositis was low; no rhabdomyolysis was reported. Elevations in liver enzymes were rare in this subgroup. Incidence of CK elevations was low, as were elevations in creatinine. Similar to the overall population, no new or unexpected adverse events were observed with 52-week exposure to fenofibric acid in combination with moderate-dose statin in the present analysis. 
The primary limitations of this study are the open-label nature of the extension study, the post hoc nature of the analysis, and small size $(N=92)$ of the subgroup. Other limitations of the study are that all patients were treated with combination therapy and no comparisons with placebo or individual monotherapies were made. Additionally, although this analysis evaluated the effects of adding fenofibric acid to moderate-dose statin therapy on several lipid and apolipoprotein parameters, only reductions in LDL-C has been correlated with favorable cardiovascular outcomes.

\section{Conclusions}

In conclusion, this analysis evaluating the efficacy and safety of adding fenofibric acid to moderate-dose statin therapy over 52 weeks in a subgroup of patients with LDL$\mathrm{C}<100 \mathrm{mg} / \mathrm{dL}$ and $\mathrm{TG}>200 \mathrm{mg} / \mathrm{dL}$ showed that the secondary treatment target of non-HDL-C, along with ApoB, TG, and HDL-C were all improved with combination therapy compared with statin monotherapy with an acceptable safety profile.

Acknowledgments This study was funded by Abbott. Christie Ballantyne has received grant/research support (paid to institution, not individual) from Abbott, AstraZeneca, GlaxoSmithKline, Merck, Sanofi-Synthelabo, Schering-Plough, Takeda, NIH, ADA, and AHA; is a consultant for Abbott, Amylin, Bristol-Myers Squibb, Kowa, Merck/Schering-Plough, Metabasis, NicOx, Novartis, Pfizer, Resverlogix, Roche, Sanofi-Synthelabo, Schering-Plough, and Takeda; serves on the speaker's bureau of Abbott, AstraZeneca, GlaxoSmithKline, and Merck; and has received honorarium from Abbott, AstraZeneca, GlaxoSmithKline, Merck, Novartis, Roche, SanofiSynthelabo, Schering-Plough, and Takeda. Peter Jones has received honoraria for speaking from Merck/Schering Plough, Abbott, and AstraZeneca; and for consulting from Abbott, Roche/Genentech, Atherotec and AstraZeneca. Maureen Kelly, Carolyn Setze, Aditya Lele, Kamlesh Thakker, and James Stolzenbach are employees of Abbott. We thank Hsiaoming Sun of Abbott for assistance with statistical analyses, Andrea Byars of Abbott for assistance with clinical study management, and Geeta Thakker of Abbott for assistance with medical writing and manuscript preparation.

Open Access This article is distributed under the terms of the Creative Commons Attribution Noncommercial License which permits any noncommercial use, distribution, and reproduction in any medium, provided the original author(s) and source are credited.

\section{References}

1. Stanek EJ, Sarawate C, Willey VJ, Charland SL, Cziraky MJ. Risk of cardiovascular events in patients at optimal values for combined lipid parameters. Curr Med Res Opin. 2007;23:553-63.

2. Assmann G, Schulte H. Relation of high-density lipoprotein cholesterol and triglycerides to incidence of atherosclerotic coronary artery disease (the PROCAM experience). Prospective Cardiovascular Munster study. Am J Cardiol. 1992;70:733-7.
3. Hokanson JE, Austin MA. Plasma triglyceride level is a risk factor for cardiovascular disease independent of high-density lipoprotein cholesterol level: a meta-analysis of population-based prospective studies. J Cardiovasc Risk. 1996;3:213-9.

4. Assmann G, Schulte H, Cullen P, Seedorf U. Assessing risk of myocardial infarction and stroke: new data from the Prospective Cardiovascular Munster (PROCAM) study. Eur J Clin Invest. 2007;37:925-32.

5. Third Report of the National Cholesterol Education Program (NCEP) Expert Panel on Detection, Evaluation, and Treatment of High Blood Cholesterol in Adults (Adult Treatment Panel III) final report. Circulation. 2002;106:3143-421.

6. Jones PH, Davidson MH, Kashyap ML, Kelly MT, Buttler SM, Setze CM, et al. Efficacy and safety of ABT-335 (fenofibric acid) in combination with rosuvastatin in patients with mixed dyslipidemia: a phase 3 study. Atherosclerosis. 2009;204:208-15.

7. Mohiuddin SM, Pepine CJ, Kelly MT, Buttler SM, Setze CM, Sleep DJ, et al. Efficacy and safety of ABT-335 (fenofibric acid) in combination with simvastatin in patients with mixed dyslipidemia: a phase 3, randomized, controlled study. Am Heart J. 2009;157:195-203.

8. Goldberg AC, Bays HE, Ballantyne CM, Kelly MT, Buttler SM, Setze CM, et al. Efficacy and safety of ABT-335 (fenofibric acid) in combination with atorvastatin in patients with mixed dyslipidemia. Am J Cardiol. 2009;103:515-22.

9. Bays HE, Jones PH, Mohiuddin SM, Kelly MT, Sun H, Setze $\mathrm{CM}$, et al. Long-term safety and efficacy of fenofibric acid in combination with statin therapy for the treatment of patients with mixed dyslipidemia. J Clin Lipidol. 2008;2:426-35.

10. Brunzell JD, Davidson M, Furberg CD, Goldberg RB, Howard $\mathrm{BV}$, Stein JH, et al. Lipoprotein management in patients with cardiometabolic risk: consensus conference report from the American Diabetes Association and the American College of Cardiology Foundation. J Am Coll Cardiol. 2008;51:1512-24.

11. Farnier M, Salko T, Isaacsohn JL, Troendle AJ, Dejager S, Gonasun L. Effects of baseline level of triglycerides on changes in lipid levels from combined fluvastatin+fibrate (bezafibrate, fenofibrate, or gemfibrozil). Am J Cardiol. 2003;92:794-7.

12. Elisaf M. Effects of fibrates on serum metabolic parameters. Curr Med Res Opin. 2002;18:269-76.

13. Fazio S, Linton MF. The role of fibrates in managing hyperlipidemia: mechanisms of action and clinical efficacy. Curr Atheroscler Rep. 2004;6:148-57.

14. Campos H, Genest Jr JJ, Blijlevens E, McNamara JR, Jenner JL, Ordovas JM, et al. Low density lipoprotein particle size and coronary artery disease. Arterioscler Thromb. 1992;12:187-95.

15. Griffin BA, Freeman DJ, Tait GW, Thomson J, Caslake MJ, Packard CJ, et al. Role of plasma triglyceride in the regulation of plasma low density lipoprotein (LDL) subfractions: relative contribution of small, dense LDL to coronary heart disease risk. Atherosclerosis. 1994;106:241-53.

16. Rosenson RS, Wolff DA, Huskin AL, Helenowski IB, Rademaker AW. Fenofibrate therapy ameliorates fasting and postprandial lipoproteinemia, oxidative stress, and the inflammatory response in subjects with hypertriglyceridemia and the metabolic syndrome. Diabetes Care. 2007;30:1945-51.

17. Lemieux I, Laperriere L, Dzavik V, Tremblay G, Bourgeois J, Despres JP. A 16-week fenofibrate treatment increases LDL particle size in type IIA dyslipidemic patients. Atherosclerosis. 2002;162:363-71.

18. Karas RH, Kashyap ML, Knopp RH, Keller LH, Bajorunas DR, Davidson MH. Long-term safety and efficacy of a combination of niacin extended release and simvastatin in patients with dyslipidemia: the OCEANS study. Am J Cardiovasc Drugs. 2008;8:69-81.

19. Yokoyama M, Origasa H, Matsuzaki M, Matsuzawa Y, Saito Y, Ishikawa $\mathrm{Y}$, et al. Effects of eicosapentaenoic acid on major 
coronary events in hypercholesterolaemic patients (JELIS): a randomised open-label, blinded endpoint analysis. Lancet. 2007;369:1090-8.

20. The ACCORD Study Group. Effects of combination lipid therapy in type 2 diabetes mellitus. N Engl J Med; 362:1563-74.

21. Scott R, O'Brien R, Fulcher G, Pardy C, D'Emden M, Tse D, et al. Effects of fenofibrate treatment on cardiovascular disease risk in 9, 795 individuals with type 2 diabetes and various components of the metabolic syndrome: the Fenofibrate Intervention and Event Lowering in Diabetes (FIELD) study. Diabetes Care. 2009;32:493-8.

22. Secondary prevention by raising HDL cholesterol and reducing triglycerides in patients with coronary artery disease: the Bezafibrate Infarction Prevention (BIP) study. Circulation 2000;102:21-7.

23. Manninen V, Tenkanen L, Koskinen P, Huttunen JK, Manttari M, Heinonen OP, et al. Joint effects of serum triglyceride and LDL cholesterol and HDL cholesterol concentrations on coronary heart disease risk in the Helsinki Heart Study. Implications for treatment. Circulation. 1992;85:37-45.

24. Grundy SM, Cleeman JI, Merz CN, Brewer Jr HB, Clark LT, Hunninghake DB, et al. Implications of recent clinical trials for the National Cholesterol Education Program Adult Treatment Panel III guidelines. Circulation. 2004;110:227-39.

25. Grundy SM. Low-density lipoprotein, non-high-density lipoprotein, and apolipoprotein B as targets of lipid-lowering therapy. Circulation. 2002;106:2526-9.

26. Grundy SM, Cleeman JI, Daniels SR, Donato KA, Eckel RH, Franklin BA, et al. Diagnosis and management of the metabolic syndrome: an American Heart Association/National Heart, Lung, and Blood Institute Scientific Statement. Circulation. 2005;112:2735-52.

27. Davidson MH, Maki KC, Pearson TA, Pasternak RC, Deedwania PC, McKenney JM, et al. Results of the National Cholesterol Education (NCEP) Program Evaluation ProjecT Utilizing Novel E-Technology (NEPTUNE) II survey and implications for treatment under the recent NCEP Writing Group recommendations. Am J Cardiol. 2005;96:556-63.

28. Deedwania PC, Hunninghake DB, Bays HE, Jones PH, Cain VA, Blasetto JW. Effects of rosuvastatin, atorvastatin, simvastatin, and pravastatin on atherogenic dyslipidemia in patients with characteristics of the metabolic syndrome. Am J Cardiol. 2005;95:360-6. 